\title{
Stackelberg Game Model of Railway Freight Pricing Based on Option Theory
}

\author{
Jingwei Guo $\mathbb{D}{ }^{1}{ }^{1}$ Zhongqi Xie $\mathbb{D}^{1},{ }^{1}$ and Qinglin $\mathrm{Li} \mathbb{D}^{2}$ \\ ${ }^{1}$ School of Energy Science and Engineering, Henan Polytechnic University, Jiaozuo 454000, China \\ ${ }^{2}$ School of Transportation and Logistics, Southwest Jiaotong University, Chengdu 610031, China \\ Correspondence should be addressed to Qinglin Li; lql@my.swjtu.edu.cn
}

Received 14 November 2019; Revised 19 May 2020; Accepted 4 June 2020; Published 22 June 2020

Academic Editor: Emilio Jiménez Macías

Copyright (c) 2020 Jingwei Guo et al. This is an open access article distributed under the Creative Commons Attribution License, which permits unrestricted use, distribution, and reproduction in any medium, provided the original work is properly cited.

In recent years, although rail transport has contributed significantly to the productivity of the Chinese economy, it has also been faced with the fierce competition and challenge from other modes of transportation, and therefore, freight-pricing issue has received more attention by researchers. In this paper, the rail freight option (RFO) based on option theory is proposed to study the optimal pricing decision of the railway transportation enterprise and contract customers' optimal purchase decisions. To obtain an effective RFO contract, the railway freight contract transaction process is first analyzed. Then, the theoretical framework for the RFO contract trading is put forward in the railway freight market. Next, a two-stage Stackelberg game theoretic approach is presented based on the principle of utility maximization to achieve the optimal decision of RFO contract. Subsequently, the reverse reasoning method in dynamic programming is used to solve the optimal combination decision of the contract customer. Finally, the optimal pricing decision of RFO is discussed using Kuhn-Tucker conditions and Lagrangian function. The result shows that the railway transportation enterprise should pay more attention to the option strike price $w_{1}$ in terms of maximizing system utility and achieving Pareto optimal.

\section{Introduction}

Railway is one of the most efficient and environmentalfriendly ways for transportation industry in China, and it has contributed significantly to the productivity of the Chinese economy [1]. However, in the process of the continuous growth of other modes of transportation and the increasing market competitiveness, the market share of the railway freight industry has declined year by year [2]. The marketization management mode of railway freight transport is the reform trend of China's railway transport industry. Hence, the transformation to market-oriented operation must be accelerated for railway freight transport operations to adapt to changes in the transportation market, which will also benefit and help develop railway transport enterprises.

Nowadays, China's railway freight has the coexistence of contract market and spot market. In the contract market, railway transport enterprises sell part of their transport capacities by signing a contractual agreement (usually six months in advance) with the contract customer. The signing of these contracts has certain advantages in terms of stable supply and business relative to the spot market with poor transaction stability. More precisely, the contract provides stable bulk supply for railway transportation and requires transportation enterprises offering transportation guarantee for contract customers at the same time. However, during the contract period, both parties need to implement a fixed contract price and cannot profit from trading in market price fluctuations, which is unfavorable for maximizing the utility of both parties. Meanwhile, railway transport enterprises will not sell all their capacities in the contract market, and the remaining capacities can only be sold through the spot market. In the spot market, the relationship between supply and demand directly determines the freight rate, and some transactions failed due to large price fluctuations. All of these will restrict the railway transportation enterprises to formulate a market competitive freight pricing system. Therefore, the problems that how to price the freight rate of 
railway freight transportation enterprises and improve the competitiveness of railway transportation have to be settled urgently. Pricing freight rate is a complicated problem involving a range of issues; for example, firstly, there is a noncooperative game between railway transportation enterprise and contract customer. Secondly, as shown in Figure 1 [3], competitive pricing should be used that helps railway transportation enterprises gain more market share and business. Thirdly, the essence of railway transportation service requires flexibility and risk avoidance in pricing mechanism.

In real life, consider a company that uses two channels for trading: contract and spot, and several flexibility contracts were concerned by many scholars, such as return contract $[4,5]$, quantity flexibility (QF) contract [6-9], multiperiodic supply chain contracts [10-12], and risk-sharing contract $[13,14]$. These flexibility contracts are widely applied in trade agreement for its flexibility and versatility. However, asymmetric information existing in trade activities is nothing new, and the above contracts cannot help the stakeholders make rational decisions. Then, investigating the role of options (contingent claims) in a buyer-supplier system has attracted great attention from researchers [15-18]. Dawn et al. illustrated how options provide flexibility to a buyer to respond to market changes in the second period [19]. Bester and Krähmer analyzed bilateral contracting in an environment with contractual incompleteness and asymmetric information using a simple deterministic exit option contract [20]. Luca et al. studied how exit options can affect bidding behavior and the buyer's and the seller's expected payoffs in multidimensional procurement auctions [21]. Furthermore, an option tool will improve the economic efficiency of the partners in the discrete environment [22], hedge market risk [23], and promote fair trade [24]. Through numerical examples, Barnes-Schuster et al. verified the role of option contracts in improving the utility of supply chain [25]. Additional applied researches have investigated the application of options in supply chain management. Cheng et al. established a single-cycle secondary supply chain option contract model to determine the optimal pricing and ordering strategies [26]. Xing et al. derived the Seller's optimal bidding and Buyers' optimal contracting strategies in a von Stackelberg game with the Seller as the leader [27]. Wang and Tsao assumed that the option contract executed in the second stage is not equal to the option purchase amount in the first stage, and the optimal strategy is obtained from the perspective of the option buyer [28]. Cai et al. investigated the relationship between the option contract and the subsidy contract and found supply chain coordination and Pareto improvement can be achieved by introducing the option contract [29]. Liu et al. investigate the coordination of both the supplier-led and the retailer-led supply chains under option contract [30]. All of those have largely promised the potential for option contracts' applications to develop freight derivatives.

Like options on stocks, options on freight provide stakeholders with protection against adverse freight rate movements. Increased globalization and increased demand for transportation has resulted in freight itself becoming a volatile commodity. In the freight transaction area, Rolf et al. established a capacity option pricing model and applied option contract into air cargo industry [31]. Koekebakker et al. set up the theoretical framework for the valuation of the Asian-style options traded in the shipping market [32]. Soltani et al. considered a commodity processor and developed models to determine the ocean freight firm's optimal hedging policy [33]. Kyriakou et al. developed an accurate valuation setup for freight options, featuring an exponential mean-reverting model for the freight rate with distinct reversion scales for its jump and diffusion components [34]. Although freight options has been the primary tool used to manage fluctuations in the shipping due to volatile ship prices, the contracts were never traded [35]. For sea transport enterprises, the purpose of buying options is to hedge risks rather than exercise options [36]. By contrast, railway transportation enterprises adopt option trading to improve the competitiveness of railway transportation. As railway transportation market is relatively new, not much scientific research has been done in this area. Guo and Peng applied the option theory into railway freight pricing activities and established a multiphase trigeminal tree pricing model [37]. Meanwhile, a multiphase trigeminal tree pricing model with jump diffusion process was established to depict the fluctuations in RFO pricing strategy caused by the nonmarketing uncertainty which arrive at random discrete time points [38]. These have a certain reference value for studying the pricing of RFO. However, these studies are independent of the optimal decentralized decision of the supply chain system, and its pricing strategy is not conducive to the long-term stability of the supply chain.

In this paper, a two-stage Stackelberg game model of railway transport enterprise and contract customer is developed based on the perspective of coordinating supply chain. The main contributions of this paper are summarized as follows:

(1) Considering the coexistence of contract market and spot market, a new tradable RFO is designed and the transaction process is elaborated

(2) A two-stage Stackelberg game theoretic approach based on the principle of supply chain utility maximization is proposed to achieve the optimal decision of RFO contract

(3) A new reverse reasoning algorithm is proposed to deal with the optimal decision of contract customer

(4) Combined Lagrangian function with Kuhn-Tucker conditions, a new method is put forward to obtain the optimal pricing decision of RFO

The remainder of this article is organized as follows: Section 2 details the methodology; Section 3 presents the method for obtaining the contract customers' optimal decision, and the optimal pricing decision of RFO is derived in Section 4; and Section 5 will conclude our work. 


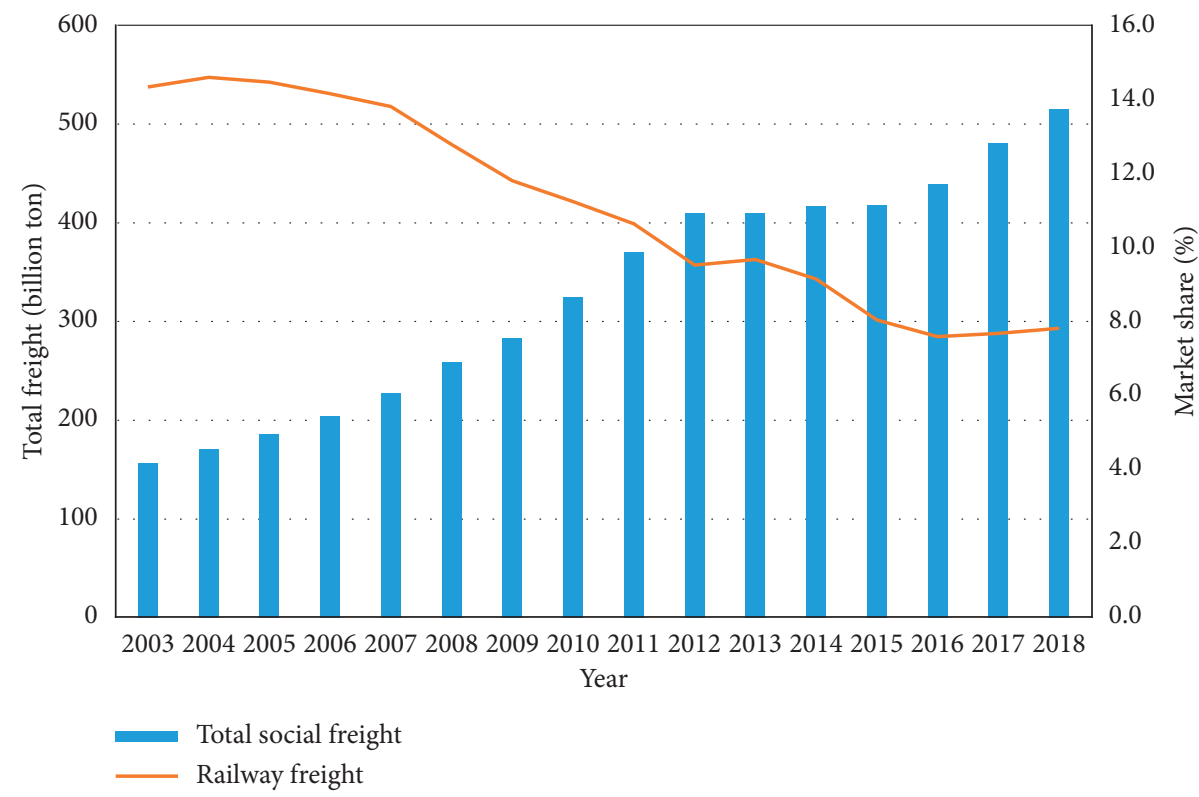

FIgURE 1: Total freight volume and rail freight volume in China.

\section{Model Description}

2.1. Definition of RFO. Freight has to be contracted, just like commodities. The only difference is that most commodities are real products, while freight is a service instead of a physical product [39]. So when freight is "bought," the service of products being transported is contracted. Due to nonstorability of freight, it should be traded in time. To protect railway transport enterprises and contract customers against market risks, a new option contract related to freight is provided according to the concept of options in the financial market, called rail freight option (RFO). Unlike other options, RFO helps railway transport enterprises selling nonstorable freight in advance and also insures stakeholders against freight rates moving beyond a specified price level.

Definition 1. A RFO is a call option contract which states that the contract customer (holder) has the right to pay/ receive the average of the values of the freight rates during some period on or before the expiration date and receive/pay strike price. The railway transport enterprise (writer) then has the obligation to receive/pay this average and pay/receive the strike price when the holder decides to exercise.

In fact, a RFO is an option contract for an asset that is subject to the railway freight transport service. The railway transport enterprise is the option that writer has the right, but not the obligation, to sell the option at the option price. And the contract customer is the holder who is a purchaser of option. If the execution price of the expiration date is higher than the spot market price, the contract customer will pay the execution fee and execute RFO; otherwise, the contract customer will abandon the execution right of RFO and choose to purchase the capacity in the spot market. With an option, the contract customer has no risk of losing any money more than strike price due to freight price volatility because he always has the possibility not to exercise RFO. For the railway transportation enterprise, if contract customer gives up the execution of RFO, they will sell the capacities in the spot market without refunding the option fees. This is a way the railway transportation enterprise can spread risk and schedule the freight train plans rationally. Under such circumstances, although the risk avoidance is realized effectively, the feasibility of decision-making process is another issue that should be considered.

2.2. Transaction Process Description. In practice, both railway transportation enterprise and contract customer are mostly partial to risk aversion just to have different degree. Therefore, the degree of risk acceptability determines the amount of options purchased. The vast majority of existing studies deal with how to use option for hedging. The optimal decision is a decentralized decision that is independent of the utility of the supply chain. Excessive pursuit of maximization of its own utility based on decentralized decision is not conducive to the long-term stability of the entire supply chain. The expectation of maximizing returns is not the optimal decision point in terms of transportation system. Compared with the existing studies focus on the expected returns of stakeholders, this paper studies the decisionmaking in the RFO trading to help maximize system utility, maintain the long-term development of the entire supply chain, and achieve Pareto optimal.

Consider a railway transportation enterprise who is looking to protect the company against a possible decrease in the freight rates. To this extent, the railway transportation enterprise writes and sells the RFO by speculating contract customer buying behavior so as to formulate reasonable option prices and circulation. Then, contract customer determines the purchase amount of RFO according to the pricing announced by the railway transportation enterprise. 
And in the second stage, the contract customer will decide whether or not to exercise his RFO. If only the total amount that the contract customer has to add up to the option strike price is less than the spot freight rate at that point, the contract customer will exercise his RFO, and of course, the contract customer will abandon his RFO in reverse. The transaction process actually conforms to the two-stage dynamic game model and is shown in Figure 2.

2.3. Symbol and Assumption. To better understand the model, the list of all the notations used in our work is presented in Table 1. Some notations will be more precisely defined as they appear in later sections of this paper.

In order to build the mathematical model, this study makes the following assumptions:

Assumption 1. The RFO covered in this article is European call option; that is to say, RFO can only be executed on the expiration date.

Assumption 2. Both railway transport enterprises and contract customers are completely rational and risk averse. In order to maximize system utility and achieve Pareto optimal, the optimal decision is based on the principle of maximizing supply chain utility as much as possible.

Assumption 3. The freight rate of the spot market in this model is an exogenous variable, which is completely dominated by the external market economic conditions, and is not affected by the railway transportation enterprises and contract customers.

Assumption 4. Both contract market and spot market have a normal distribution of freight demand; $\mu$ and $\sigma$ represent the mean and standard deviation, respectively.

2.4. Stackelberg Model Construction. In the case of contract market coexisting with spot market, two-stage Stackelberg game model is established, in which the railway transportation enterprise is the leader and the contract customer is the follower. The game sequence is shown as the following:

Step 1: in the contract market of time $T_{0}$, the railway transport enterprise writes the RFO including the option price $w_{0}$ and the option strike price $w_{1}$.

Step 2: according to the published price strategy of RFO $(N)$, the contract customer decides the purchase amount of RFO to maximize their expected returns.

Step 3: in the spot market of time $T_{1}$, the contract customer will decide whether or not to exercise his RFO based on the spot market freight rate $p_{i}$ and the option strike price $w_{1}$. Furthermore, determine the execution amount of RFO $\left(q_{1}\right)$ and the capacity purchases amount through spot market $\left(q_{2}\right)$. Thus, the utility function of contract customer $\pi_{1}\left(q_{1}, q_{2}, p_{i}, N\right)$ can be expressed as follows: $\pi_{1}\left(q_{1}, q_{2}, p_{i}, N\right)=U\left(q_{1}+q_{2}\right)-w_{0} N-w_{1} q_{1}-p_{i} q_{2}$,

where $U\left(q_{1}+q_{2}\right)$ stands for the market return expected by the contract customer and $U\left(q_{1}+q_{2}\right)=$ $e^{\alpha}-e^{\alpha-\beta\left(q_{1}+q_{2}\right)} / \beta$ is assumed based on risk aversion theory, in which $\alpha$ and $\beta$ are undetermined parameters. $w_{0} N$ is the payment for the contract customer to purchase RFO, $w_{1} q_{1}$ stands for the option strike price paid by the contract customer exercising RFO, and $p_{i} q_{2}$ represents the cost of purchasing the capacity from spot market.

Step 4: similarly, the utility function of railway transportation enterprise $\pi_{2}\left(w_{0}, w_{1}, b_{0}, b_{1}, N\right)$ can be easily gained as follows:

$$
\begin{aligned}
\pi_{2}\left(w_{0}, w_{1}, b_{0}, b_{1}, N\right)= & w_{0} N+w_{1} q_{1}-b_{1} q_{1} \\
& +\left[(K-N) \wedge D_{2}\right]\left[p_{i}-b_{2}\right]^{+}-K C,
\end{aligned}
$$

where $b_{1} q_{1}$ stands for the long-term preparation cost of transportation, $\left[(K-N) \wedge D_{2}\right]\left[p_{i}-b_{2}\right]^{+}$stands for the proceeds from the sale of the remaining capacity in the spot market, and $K C$ stands for the fixed production cost [40].

Step 5: then, the utility function of system $\pi$ is obtained as follows:

$$
\begin{aligned}
\pi= & \pi_{1}+\pi_{2}=U\left(q_{1}+q_{2}\right)-p_{i} q_{2}-b_{1} q_{1} \\
& +[(K-N) \wedge D]\left[p_{i}-b_{2}\right]^{+}-K C .
\end{aligned}
$$

It is worth noting how the game reaches the Nash equilibrium. Both misjudgment of the market and the behavior of the opponent will lead to the deviation of the decision. Once the deviation occurs, one party will inevitably obtain excess profits. The other party will inevitably adjust the decision or withdraw from the market to choose alternatives. It is extremely unfavorable to the supply chain relationship. In order to maximize system utility, the longterm development of the supply chain is maintained and Pareto optima is achieved, and optimal decision should be investigated from the perspective of maximizing the utility of the supply chain.

\section{Optimal Decision of Contract Customer}

According to the order of decision, this paper uses the reverse reasoning method in dynamic programming to solve the optimal combination decision of the contract customer firstly. The problem of the contract customer optimal decision is decomposed into the following two stages:

Step 1: the constraint optimization method is used to solve the optimal combination $\left(q_{1}^{*}, q_{2}^{*}\right)$ of the RFO execution amount and the spot market purchase amount 


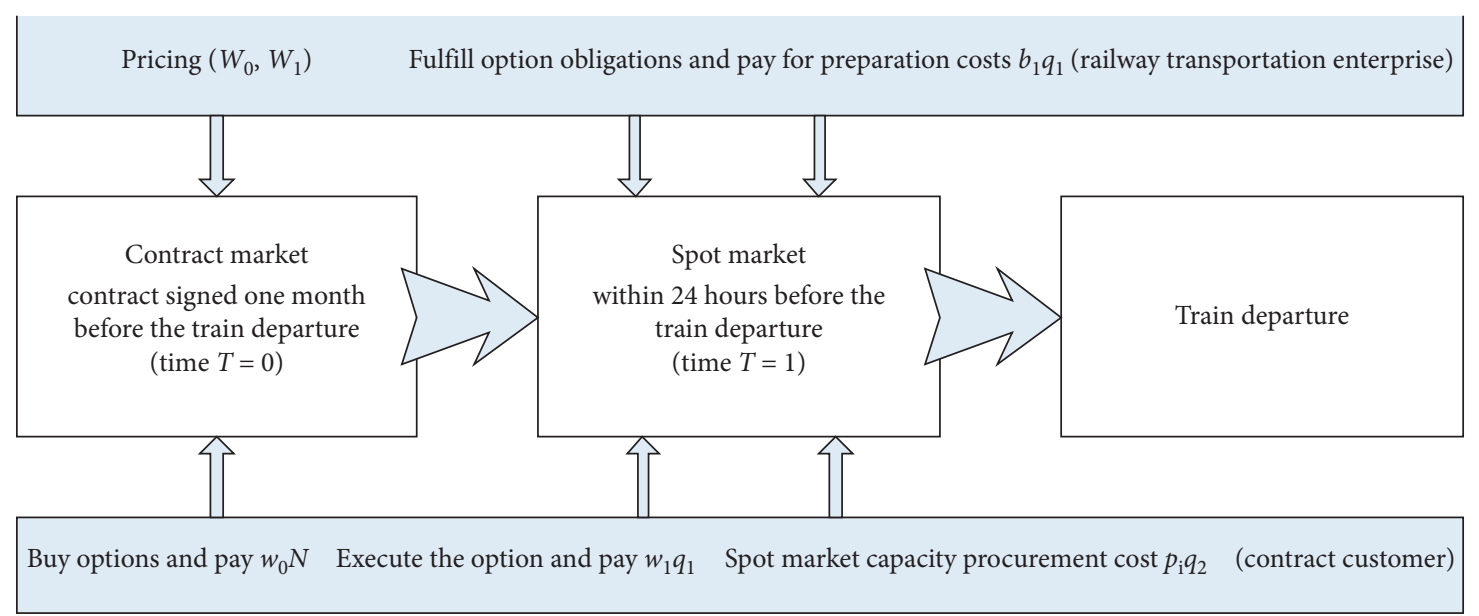

FIgURE 2: The transaction process of RFO.

TABLE 1: Summary of notations.

\begin{tabular}{lc}
\hline Notation & Descriptions \\
\hline$w_{0}$ & Option price (unit capacity) \\
$w_{1}$ & Option strike price (unit capacity) \\
$p_{i}$ & Spot market freight rate (unit capacity) in time \\
$h\left(p_{i}\right)$ & Probability density function of $p_{i}$ \\
$H\left(p_{i}\right)$ & Distribution function of $p_{i}$ \\
$N$ & Purchase amount of RFO \\
$C$ & Unit capacity fixed cost \\
$q_{1}$ & Execution amount of RFO \\
$q_{2}$ & Capacity purchases amount through spot market \\
$b_{1}$ & Long-term preparation cost of transportation (unit \\
& capacity) \\
$b_{2}$ & Short-term preparation cost of transportation (unit \\
$K$ & capacity) \\
$D_{1}$ & Total capacity provided by railway freight transport \\
$D_{2}$ & Contract market capacity demand \\
$f(D)$ & Spot market capacity demand \\
$\mu$ & Probability density function of freight demand \\
$\sigma$ & Mean deviation \\
\hline
\end{tabular}

Step 2: the optimal RFO order quantity $N^{*}$ of contract customer is solved according to the optimal combination $\left(q_{1}^{*}, q_{2}^{*}\right)$ obtained in the first stage

3.1. Calculation of the Optimal Combination. The goal of the contract customer is to maximize its own expected utility, which can be expressed as the following optimization problem with constraints:

$$
\begin{array}{ll}
\max _{q_{1}, q_{2}} & E\left[\pi\left(q_{1}, q_{2}, p_{i}, N\right)\right] \\
\text { s.t } & q_{2} \geq 0, q_{1} \leq N, 0 \leq q_{2} \leq D_{2} .
\end{array}
$$

According to formula (4), the RFO execution amount and the spot market purchase amount of the contract customer are obtained as described in Theorem 1.

Theorem 1. The optimal choice of RFO execution can be expressed as follows:

$$
q_{1}^{*}= \begin{cases}N, & w_{1} \leq p_{i}, \\ 0, & w_{1}>p_{i} .\end{cases}
$$

The optimal choice of the capacity purchases amount through spot market can be expressed as follows:

$$
q_{2}^{*}= \begin{cases}D_{2}, & w_{1}>p, \\ D_{2}-N, & \frac{\partial U}{\partial N}>p_{i} \geq w_{1}, \\ 0, & p_{i} \geq \frac{\partial U}{\partial N}>w_{1} .\end{cases}
$$

Proof. The Kuhn-Tucker conditions of formula (4) are constructed as follows:

$$
\left\{\begin{array}{l}
\tau=e^{\alpha-\beta\left(q_{1}+q_{2}\right)}-w_{0} N-w_{1} q_{1}-p_{i} q_{2}+\gamma_{1} q_{2} \\
+\gamma_{2}\left(N-q_{1}\right)+\gamma_{3} q_{1}+r_{4}\left(D_{2}-q_{2}\right) \\
\gamma_{i} \geq 0(i=1,2,3,4), q_{2} \geq 0, N-q_{1} \geq 0, q_{2} \geq 0, D_{2}-q_{2} \geq 0 \\
\gamma_{1} q_{2}=0, \gamma_{2}\left(N-q_{1}\right)=0, \gamma_{3} q_{2}=0, r_{4}\left(D_{2}-q_{2}\right)=0
\end{array}\right.
$$

Next, the first-order partial derivatives of $q_{1}$ and $q_{2}$ for function $\tau$ are obtained on the basis of Lagrange multiplier $\gamma$ as follows:

$$
\begin{gathered}
\frac{\partial \tau}{\partial q_{1}}=e^{\alpha-\beta\left(q_{1}+q_{2}\right)}-w_{1}-\gamma_{2}+\gamma_{3}=0, \\
\frac{\partial \tau}{\partial q_{2}}=e^{\alpha-\beta\left(q_{1}+q_{2}\right)}-p_{i}+\gamma_{1}-r_{4}=0 .
\end{gathered}
$$

Then, the optimal combination $\left(q_{1}^{*}, q_{2}^{*}\right)$ is discussed as follows:

(a) If $\gamma_{1}>0, \gamma_{2}=0, \gamma_{3}=0, \gamma_{4}=0, w_{1} \leq p_{i}$ is gained, and the optimal combination $\left(q_{1}^{*}, q_{2}^{*}\right)$ can be discussed as the follows: 
(1) Supposing that the marginal payment ability $\partial U / \partial N$ of the contract customer is greater than the spot market freight rate $p_{i}$, it is profitable for option customer to purchase capacity from the spot market. Hence, the optimal combination $\left(q_{1}^{*}, q_{2}^{*}\right)$ can be calculated as follows:

$$
\begin{gathered}
q_{1}^{*}=N, \\
q_{2}^{*}=D_{2}-N . \\
q_{1}^{*}=N, \\
q_{2}^{*}=0 .
\end{gathered}
$$

(b) If $\gamma_{1}=0, \gamma_{2}>0, \gamma_{3}=0$, and $\gamma_{4}=0, \quad w_{1} \leq p_{i} \quad$ is gained, and the optimal combination $\left(q_{1}^{*}, q_{2}^{*}\right)$ can be calculated as follows:

$$
q_{1}^{*}=N, q_{2}^{*}=0 \text { or } D_{2}-N
$$

(c) If $\gamma_{1}=0, \gamma_{2}=0, \gamma_{3}>0$, and $\gamma_{4}=0, \quad w_{1} \geq p_{i} \quad$ is gained, and the optimal combination $\left(q_{1}^{*}, q_{2}^{*}\right)$ can be calculated as follows:

$$
\begin{aligned}
& q_{1}^{*}=0, \\
& q_{2}^{*}=D_{2} .
\end{aligned}
$$

(d) If $\gamma_{1}=0, \gamma_{2}=0, \gamma_{3}=0$, and $\gamma_{4}>0, \quad w_{1} \geq p_{i}$ is gained, and the optimal combination $\left(q_{1}^{*}, q_{2}^{*}\right)$ can be calculated as follows:

$$
\begin{aligned}
& q_{1}^{*}=N, \\
& q_{2}^{*}=0 .
\end{aligned}
$$

(2) Conversely, if $\partial U / \partial N-p_{i} \leq 0$, the contract customer blindly purchasing the capacity in the spot market will reduce its profit. The optimal choice is to stop the repurchase of capacity. Hence, the optimal combination $\left(q_{1}^{*}, q_{2}^{*}\right)$ can be calculated as follows:

Therefore, Theorem 1 is proved.

In addition, this article finds an interesting conclusion that the contract customer's RFO execution is greatly affected by the option strike price $w_{1}$. If only the option strike price $w_{1}$ is smaller than spot market freight rate $p_{i}$ and the market demand is much larger than its RFO purchase amount $N$, the contract customer will choose to execute all RFO purchased. On the contrary, it will choose to abandon RFO and instead purchase the capacity in the spot market to obtain higher profits.

3.2. Optimal RFO Order Quantity of Contract Customer. According to the optimal combination $\left(q_{1}^{*}, q_{2}^{*}\right)$ obtained, the original utility function independent variable is changed based on the principle of utility maximization, and formula (4) can be updated as follows:

$$
\begin{array}{ll}
\max _{N} & E\left[\pi\left(w_{1}, N\right)\right] \\
\text { s.t } & N \geq 0 .
\end{array}
$$

Then, solving mathematical program with constraints in formula (14), the optimal RFO order quantity $N^{*}$ of the contract customer is obtained as described in Theorem 2.

Theorem 2. Based on the option price written by railway transport enterprise, the contract customer decides the optimal option purchase amount $N^{*}$ satisfies the following formula:

$$
\begin{aligned}
& U^{\prime}\left(N^{*}\right)\left[1-H\left(U^{\prime}\left(N^{*}\right)\right)\right] \\
& \quad+\int_{0}^{\partial U / \partial N} H\left(p_{i}\right) d p_{i}=\left(b_{1}+w_{1}+p_{i}-b_{2}\right) H\left(p_{i}\right)+p_{i} .
\end{aligned}
$$

Proof. Substituting formula (3) into formula (15), the objective function of formula (15) can be updated as follows:

$$
\begin{aligned}
\pi= & U\left(q_{1}+q_{2}\right)-p_{i} q_{2}-b_{1} q_{1}+\left[(K-N) \wedge D_{2}\right]\left[p_{i}-b_{2}\right]^{+}-K C \\
= & E U\left(q_{1}+q_{2}\right)-p_{i}\left(D_{2}-q_{1}\right)^{+}-b_{1} \int_{w_{1}}^{\infty} N h\left(p_{i}\right) \mathrm{d} p_{i} \\
& +\left[p_{i}-b_{2}\right]^{+}\left[\int_{0}^{K-N} D_{2} f\left(D_{2}\right) \mathrm{d} D_{2}+\int_{K-N}^{\infty}(K-N) f\left(D_{2}\right) \mathrm{d} D_{22}\right]-K C \\
= & E U\left(q_{1}+q_{2}\right)-b_{1} \int_{w_{1}}^{\infty} w_{1} h\left(p_{i}\right) \mathrm{d} p_{i} \int_{0}^{N} D_{1} f\left(D_{1}\right) \mathrm{d} D_{1}-\int_{w_{1}}^{\infty} w_{1} h\left(p_{i}\right) \mathrm{d} p_{i} \int_{N}^{\infty} N f\left(D_{1}\right) \mathrm{d} D_{1} \\
& -b_{1} \int_{w_{1}}^{\infty} N h\left(p_{i}\right) \mathrm{d} p_{i}-\int_{w_{1}}^{\infty} N h\left(p_{i}\right) \mathrm{d} p_{i} \int_{N}^{\infty}\left(D_{1}-N\right) f\left(D_{1}\right) \mathrm{d} D_{1} \\
& +\left[p_{i}-b_{2}\right]^{+}\left[\int_{0}^{K-N} D_{2} f\left(D_{2}\right) \mathrm{d} D_{2}+\int_{K-N}^{\infty}(K-N) f\left(D_{2}\right) \mathrm{d} D_{22}\right]-K C .
\end{aligned}
$$


As $E\left[D_{1}\right]=\int_{0}^{N} f\left(D_{1}\right) \mathrm{d} D+\int_{N}^{\infty} D_{1} f\left(D_{1}\right) \mathrm{d} D_{1}$, the expected utility function of the supply chain can be expressed equivalently as

$$
\begin{aligned}
\pi= & E U\left(q_{1}+q_{2}\right)-\int_{w_{1}}^{\infty} w_{1} h\left(p_{i}\right) \mathrm{d} p_{i} \int_{0}^{N} D_{1} f\left(D_{1}\right) \mathrm{d} D_{1}-\int_{w_{1}}^{\infty} w_{1} h\left(p_{i}\right) \mathrm{d} p_{i} \int_{N}^{\infty} N f\left(D_{1}\right) \mathrm{d} D_{1} \\
& +\int_{w_{1}}^{\infty} p_{i} h\left(p_{i}\right) \mathrm{d} p_{i} \int_{N}^{\infty} N f\left(D_{1}\right) \mathrm{d} D_{1}-p_{i} E\left[D_{1}\right]+\int_{w_{1}}^{\infty} p_{i} h\left(p_{i}\right) \mathrm{d} p_{i} \int_{N}^{\infty} D_{1} f\left(D_{1}\right) \mathrm{d} D_{1} \\
& -b_{1} \int_{w_{1}}^{\infty} N h\left(p_{i}\right) \mathrm{d} p_{i}+\left[p_{i}-b_{2}\right]^{+}\left[\int_{0}^{K-N} D_{2} f\left(D_{2}\right) \mathrm{d} D_{2}+\int_{K-N}^{\infty}(K-N) f\left(D_{2}\right) \mathrm{d} D_{2}\right]-K C \\
= & E U\left(q_{1}+q_{2}\right)-p_{i} E\left[D_{1}\right]+\int_{w_{1}}^{\infty}\left(p_{i}-w_{1}\right) h\left(p_{i}\right) \mathrm{d} p_{i}\left[\int_{0}^{N} D_{1} f\left(D_{1}\right) \mathrm{d} D_{1}+\int_{N}^{\infty} N f\left(D_{1}\right) \mathrm{d} D_{1}\right] \\
& -b_{1} \int_{w_{1}}^{\infty} N h\left(p_{i}\right) \mathrm{d} p_{i}+\left[p_{i}-b_{2}\right]^{+}\left[\int_{0}^{K-N} D_{2} f\left(D_{2}\right) \mathrm{d} D_{2}+\int_{K-N}^{\infty}(K-N) f\left(D_{2}\right) \mathrm{d} D_{2}\right]-K C \\
= & E U\left(q_{1}+q_{2}\right)-p_{i} E\left[D_{1}\right]+E\left[\left(p_{i}-w_{1}\right)^{+}\right]\left[D_{1} \wedge N\right]-b_{1} q_{1} \\
& +E\left(p_{i}-b_{2}\right)^{+}\left[(K-N) \wedge D_{2}\right]-K C .
\end{aligned}
$$

Moreover, if formulas (5) and (6) are substituted into formula (18), the expected utility function of the entire supply chain can be calculated as follows:

$$
\begin{aligned}
\pi= & \int\left[U\left(q_{1}+q_{2}\right)-p_{i} D\right] h\left(p_{i}\right) \mathrm{d} p_{i}+\int\left(p_{i}-w_{1}\right)^{+} N h\left(p_{i}\right) \mathrm{d} p_{i} \\
& +\int\left(p_{i}-b_{2}\right)^{+}(K-N) h\left(p_{i}\right) \mathrm{d} p_{i}-b_{1} \int_{w_{1}}^{\infty} N h\left(p_{i}\right) \mathrm{d} p_{i}-K C \\
= & \int_{0}^{\partial U / \partial N}\left\{U\left[D\left(p_{i}\right)\right]-p_{i} D\left(p_{i}\right)\right\} \mathrm{d} h\left(p_{i}\right)+\int_{\partial U / \partial N}^{\infty}\left[U(N)-p_{i} N\right] \mathrm{d} h\left(p_{i}\right) \\
& +\int_{w_{1}}^{\infty}\left(p_{i}-w_{1}\right) N \mathrm{~d} h\left(p_{i}\right)+\int_{w_{1}}^{\infty}\left(p_{i}-b_{2}\right)(K-N) \mathrm{d} h\left(p_{i}\right)-\int_{w_{1}}^{\infty} b_{1} N \mathrm{~d} h\left(p_{i}\right)-K C .
\end{aligned}
$$

Next, taking the first-order partial derivative with respect to $N$ for formula (19), the optimality conditions of first order can be calculated as follows:

$$
\begin{aligned}
\frac{\partial \pi}{\partial N} & =\int_{\partial U / \partial N}^{\infty}\left[U^{\prime}(N)-p_{i}\right] \mathrm{d} H\left(p_{i}\right)+\int_{w_{1}}^{\infty}\left(p_{i}-w_{1}\right) \mathrm{d} H\left(p_{i}\right)-\int_{w_{1}}^{\infty}\left(p_{i}-b_{2}\right) \mathrm{d} H\left(p_{i}\right)-\int_{w_{1}}^{\infty} b_{1} \mathrm{~d} H\left(p_{i}\right) \\
& =\int_{\partial U / \partial N}^{\infty}\left[U^{\prime}(N)-p_{i}\right] \mathrm{d} H\left(p_{i}\right)+\int_{w_{1}}^{\infty}\left(b_{2}-b_{1}-w_{1}\right) \mathrm{d} H\left(p_{i}\right) \\
& =E\left[U^{\prime}(N)-p_{i}\right]-\int_{\partial U / \partial N}^{\infty}\left[U^{\prime}(N)-p_{i}\right] \mathrm{d} H\left(p_{i}\right)+E\left(b_{2}-b_{1}-w_{1}\right)-\left(b_{2}-b_{1}-w_{1}\right)\left[1-H\left(p_{i}\right)\right] \\
& =U^{\prime}(N)\left[1-H\left(U^{\prime}(N)\right)\right]-\int_{0}^{\partial U / \partial N} p_{i} \mathrm{~d} H\left(p_{i}\right)-p_{i}+\left(b_{2}-b_{1}-w_{1}\right) H\left(p_{i}\right) \\
& =U^{\prime}(N)\left[1-H\left(U^{\prime}(N)\right)\right]-p_{i} H\left(p_{i}\right)-p_{i}+\int_{0}^{\partial U / \partial N} H\left(p_{i}\right) d p_{i}-p_{i}+\left(b_{2}-b_{1}-w_{1}\right) H\left(p_{i}\right) .
\end{aligned}
$$


In addition, take the second derivative with respect to $N$ for formula (20) to get $\partial^{2} \pi / \partial N^{2}=U^{\prime \prime}(N)$.

In accordance with Assumption 2, the article has $\partial^{2} \pi / \partial N^{2}=U^{\prime \prime}(N) \leq 0$ as the result of the contract customer is a risk averse. That is to say, $\pi\left(w_{0}, w_{1}, N\right)$ is a concave function with respect to $N$. Let $\partial \pi / \partial N=0$, then the optimal option purchase amount $N^{*}$ satisfies the following formula:

$$
\begin{aligned}
& U^{\prime}\left(N^{*}\right)\left[1-H\left(U^{\prime}\left(N^{*}\right)\right)\right] \\
& \quad+\int_{0}^{\partial U / \partial N} H\left(p_{i}\right) \mathrm{d} p_{i}=\left(b_{1}+w_{1}+p_{i}-b_{2}\right) H\left(p_{i}\right)+p_{i} .
\end{aligned}
$$

Therefore, Theorem 2 is proved.

Theorem 3. The optimal option purchase amount $N^{*}$ of the contract customer is monotonously decreasing with respect to the option strike price $w_{1}$.

Proof. For formula (16), taking total differentiation with respect to the option strike price $w_{1}$ using Newton-Leibniz formula, formula (22) is obtained:

$$
\frac{\partial N^{*}}{\partial w_{1}}=\frac{H\left(p_{i}\right)}{U^{\prime \prime}\left(N^{*}\right)}<0 .
$$

Obviously, if the railway transport enterprise increases the option strike price $w_{1}$, the optimal option purchase amount $N^{*}$ of the contract customer will be reduced accordingly.

\section{Optimal Pricing Decision of RFO}

4.1. Optimal Option Strike Price of RFO. Under the circumstance of contract market coexisting with spot market, the article should not focus on the decentralized decisionmaking between contract customers and railway transport enterprises, but the equilibrium of supply chain system. Therefore, according to the principle of supply chain utility maximization and formula (13), a programming optimization model is established as follows:

$$
\begin{aligned}
& \Gamma= \max _{w_{1}}\left\{E U\left(q_{1}+q_{2}\right)-p_{i} E\left[D_{1}\right]\right. \\
&+E\left[\left(p_{i}-w_{1}\right)^{+}\right]\left[D_{1} \wedge N^{*}\right] \\
&\left.-b_{1} q_{1}+E\left(p_{i}-b_{2}\right)^{+}\left[\left(K-N^{*}\right) \wedge D_{2}\right]-K C\right\}, \\
& \text { s.t } \quad w_{1} \geq 0 .
\end{aligned}
$$

According to the proof of Theorem 2, formula (23) can be rewritten as follows:

$$
\begin{aligned}
\Gamma= & \int_{0}^{\partial U / \partial N}\left\{U\left[D\left(p_{i}\right)\right]-p_{i} D\left(p_{i}\right)\right\} \mathrm{d} h\left(p_{i}\right)+\int_{\partial U / \partial N}^{\infty}\left[U(N)-p_{i} N\right] \mathrm{d} h\left(p_{i}\right) \\
& +\int_{w_{1}}^{\infty}\left(p_{i}-w_{1}\right) N \mathrm{~d} h\left(p_{i}\right)+\int_{w_{1}}^{\infty}\left(p_{i}-b_{2}\right)(K-N) \mathrm{d} h\left(p_{i}\right)-\int_{w_{1}}^{\infty} b_{1} N \mathrm{~d} h\left(p_{i}\right)-K C \\
= & \int_{0}^{\partial U / \partial N}\left\{U\left[D\left(p_{i}\right)\right]-p_{i} D\left(p_{i}\right)\right\} \mathrm{d} h\left(p_{i}\right)+\int_{\partial U / \partial N}^{\infty}\left[U(N)-p_{i} N\right] \mathrm{d} h\left(p_{i}\right) \\
& +\int_{w_{1}}^{\infty}\left[\left(p_{i}-w_{2}\right) K+\left(b_{2}-b_{1}-w_{1}\right) \mathrm{d} h\left(p_{i}\right)\right]-K C .
\end{aligned}
$$

Using Kuhn-Tucker conditions to solve formula (23), the optimal option strike price $w_{1}{ }^{*}$ of RFO can be obtained, as described in Theorem 4:

Theorem 4. The optimal option strike price $w_{1}{ }^{*}$ of RFO satisfies the following formula:

$$
\begin{aligned}
& \left(b_{2} K+b_{2} N^{*}-p_{i} K-b_{1} N^{*}-w_{1}^{*} N^{*}\right) h\left(w_{1}^{*}\right) \\
& +\left[\left(b_{2}-b_{1}-w_{1}^{*}\right)\left(1-\psi\left(z_{w_{1}}\right)\right)-p_{i}\left(1-\psi\left(z_{U^{*}}\right)\right)\right] \\
& \quad \frac{H\left(p_{i}\right)}{U^{\prime \prime}\left(N^{*}\right)}-N^{*}\left(1-\psi\left(z_{w_{1}}\right)\right)=0, \quad l_{1} w_{1}^{*}=0, l_{1} \geq 0 .
\end{aligned}
$$

Proof. The Kuhn-Tucker conditions of formula (23) are constructed as follows:

$$
\left\{\begin{array}{l}
\frac{\partial \vartheta}{\partial w_{1}}=\frac{\partial \Gamma}{\partial w_{1}}+l_{1}=0 \\
\vartheta=\Gamma+l_{1} w_{1}, \\
l_{1} \geq 0 \\
l_{1} w_{1}=0 .
\end{array}\right.
$$

Next, take the first-order partial derivative with respect to $w_{1}$ for the Lagrangian function $\vartheta$ as follows: 


$$
\begin{aligned}
\frac{\partial \Gamma}{\partial w_{1}}= & \frac{\partial}{\partial w_{1}}\left\{\left(p_{i}-b_{2}\right) K \int_{w_{1}}^{\infty} h\left(p_{i}\right) d p_{i}+\left(b_{2}-b_{1}-w_{1}\right) N^{*} \int_{w_{1}}^{\infty} h\left(p_{i}\right) d p_{i}\right\}-\frac{\partial N^{*}}{\partial w_{1}} p_{i} \int_{\partial U / \partial N_{1}}^{\infty} h\left(p_{i}\right) \mathrm{d} p_{i}+l_{1} \\
= & \left(b_{2}-p_{i}\right) K h\left(w_{1}\right)-N^{*} \int_{w_{1}}^{\infty} h\left(p_{i}\right) \mathrm{d} p_{i}+\left(b_{2}-b_{1}-w_{1}\right) N^{*} h\left(w_{1}\right) \\
& +\frac{\partial N^{*}}{\partial w_{1}}\left(b_{2}-b_{1}-w_{1}\right) \int_{w_{1}}^{\infty} h\left(p_{i}\right) \mathrm{d} p_{i}-\frac{\partial N^{*}}{\partial w_{1}} p_{i} \int_{\partial U / \partial N_{1}}^{\infty} h\left(p_{i}\right) d p_{i}+l_{1} \\
= & \left(b_{2} K+b_{2} N^{*}-p_{i} K-b_{1} N^{*}-w_{1} N^{*}\right) h\left(w_{1}\right) \\
& +\left[\left(b_{2}-b_{1}-w_{1}\right)\left(1-\psi\left(z_{w_{1}}\right)\right)-p_{i}\left(1-\psi\left(z_{U^{\prime}}\right)\right)\right] \frac{\partial N^{*}}{\partial w_{1}}-N^{*}\left[1-\psi\left(z_{w_{1}}\right)\right]
\end{aligned}
$$

in which $z_{w_{1}}=w_{1}-\mu_{D_{2}} / \sigma_{D_{2}}$ and $\psi\left(z_{w_{1}}\right)=\int_{-\infty}^{w_{1}} f(t) \mathrm{d} t$.

Then, substituting formulas (22) and (27) into formula (26), formula (25) is obtained.

Therefore, Theorem 4 is proved.

4.2. Optimal Option Price of RFO. Considering the optimal option purchase amount $N^{*}$ and optimal option strike price $w_{1}^{*}$ calculated above, the original utility function independent variable is changed based on the principle of supply chain utility maximization. Therefore, the constraint problem of satisfying the optimal option price $w_{0}^{*}$ can be updated as follows:

$$
\begin{array}{ll}
\Pi= & w_{0} N+w_{1}^{*} q_{1}-b_{1} q_{1}+\left[\left(K-N^{*}\right) \wedge D_{2}\right]\left[p_{i}-b_{2}\right]^{+}-K C, \\
\text { s.t } \quad w_{0} \geq 0 .
\end{array}
$$

According to the proof of Theorem 2, formula (28) can be rewritten as follows:

$$
\begin{aligned}
\Pi= & w_{0} N+\left(w_{1}-b_{1}\right) \int_{w_{1}}^{\infty} N h\left(p_{i}\right) \mathrm{d} p_{i}+\left[p_{i}-b_{2}\right]^{+} \\
& \cdot\left[\int_{0}^{K-N} D_{2} f\left(D_{2}\right) \mathrm{d} D_{2}+\int_{K-N}^{\infty}(K-N) f\left(D_{2}\right) \mathrm{d} D_{2}\right]-K C .
\end{aligned}
$$

Using Kuhn-Tucker conditions to solve formula (28), the optimal option price $w_{0}^{*}$ of RFO can be obtained, as described in Theorem 5 .

Theorem 5. The optimal option price $w_{0}^{*}$ of RFO satisfies the following formula:

$$
\begin{aligned}
& N^{*}+\left\{w_{0}^{*}+\left(w_{1}^{*}-b_{1}\right)\left(1-\psi\left(z_{w_{1}^{*}}\right)\right)\right. \\
& \left.\quad-\left[p_{i}-b_{2}\right]^{+}\left(1-\psi\left(z_{K-N}\right)\right)\right\} \frac{\partial N^{*}}{\partial w_{0}^{*}}=0, \quad l_{2} w_{0}^{*}=0, l_{2} \geq 0 .
\end{aligned}
$$

Proof. The Kuhn-Tucker conditions of formula (28) are constructed as follows:

$$
\left\{\begin{array}{l}
\frac{\partial \vartheta}{\partial w_{0}}=\frac{\partial \Pi}{\partial w_{0}}+l_{2}=0 \\
\vartheta=\Pi+l_{2} w_{0} \\
l_{2} \geq 0 \\
l_{2} w_{0}=0 .
\end{array}\right.
$$

Next, take the first-order partial derivative with respect to $w_{0}$ for the Lagrangian function $\vartheta$ as follows:

$$
\begin{aligned}
\frac{\partial \Pi}{\partial w_{0}}= & N^{*}+w_{0} \frac{\partial N^{*}}{\partial w_{0}}+\frac{\partial N^{*}}{\partial w_{0}}\left(w_{1}-b_{1}\right) \int_{w_{1}}^{\infty} h\left(p_{i}\right) \mathrm{d} p_{i} \\
& -\frac{\partial N^{*}}{\partial w_{0}}\left[p_{i}-b_{2}\right]^{+} \int_{K-N}^{\infty} f\left(D_{2}\right) \mathrm{d} D_{2} \\
= & N^{*}+\left\{w_{0}+\left(w_{1}-b_{1}\right)\left(1-\psi\left(z_{w_{1}}\right)\right)\right. \\
& \left.-\left[p_{i}-b_{2}\right]^{+}\left(1-\psi\left(z_{K-N}\right)\right)\right\} \frac{\partial N^{*}}{\partial w_{0}} .
\end{aligned}
$$

Then, substituting formula (32) into formula (31), formula (30) is obtained.

Therefore, Theorem 5 is proved.

4.3. Results and Discussion. The optimal pricing decision of RFO can be divided into four cases as follows:

(1) $w_{0}^{*}>0, w_{1}^{*}=0$

In this case, the amount of RFO provided by railway transportation enterprises is equal to the contract market capacity. In other words, the contract signed with the contract customer is a fixed volume contract.

(2) $w_{0}^{*}=0, w_{1}^{*}>0$

In this case, the railway transportation enterprise does not provide any RFO, and all transport capacities are sold in the spot market. In other words, the railway transportation enterprise accepts all transport capacities reservations without charging any fees. 
(3) $w_{0}^{*}>0, w_{1}^{*}>0$

In this case, the railway transportation enterprise provides both RFO and the spot market capacity, and the contract signed with the contract customer can be regarded as RFO.

(4) $w_{0}^{*}>0, w_{1}^{*}>0$

The solution is a theoretical local optimal solution without any practical economic significance.

According to the above analysis, when the railway transportation enterprise writes RFO, the option strike price $w_{1}$ should be no more than the long-term preparation cost $b_{1}$. A reasonable option price $w_{0}$ can make up for the opportunity cost of the RFO order quantity that cannot be sold in the spot market and also avoid the risk that the marginal cost is higher than the option strike price. Meanwhile, the contract customer's RFO purchase amount $N$ is negatively correlated with the strike price $w_{1}$ and the option price $w_{0}$. In addition, the strike price $w_{1}$ is more sensitive to the impact on the expected supply chain utility than the option price $w_{0}$. This is mainly because if only the total amount that the contract customer has to add up to the option strike price $w_{1}$ is less than the spot freight rate $p_{i}$ at that point, the contract customer will exercise his RFO, and of course, the contract customer will abandon his RFO in reverse. Therefore, the railway transportation enterprise should pay more attention to the strike price $w_{1}$ in terms of maximizing system utility and achieving Pareto optimal.

\section{Conclusion}

For railway freight pricing, this paper introduces the concept of option theory and proposes a new tradable rail freight option (RFO). Different from the previous works, this paper establishes a two-stage Stackelberg game model based on the perspective of maximizing the utility of the supply chain to discuss the optimal pricing strategy of RFO. Considering the coexistence of the contract market and the spot market, this study uses the reverse reasoning method in dynamic programming to solve the optimal combination decision of the contract customer firstly. Then, the optimal pricing decision of RFO is obtained using Kuhn-Tucker conditions and Lagrangian function. The main conclusions of this article are as follows: (1) the option strike price $w_{1}$ should no more than the long-term preparation cost $b_{1}$; (2) the contract customer's RFO purchase amount $N$ is negatively correlated with the strike price $w_{1}$ and the option price $w_{0}$; and (3) the railway transportation enterprise should pay more attention to the option strike price $w_{1}$ in terms of maximizing system utility and achieving Pareto optimal.

\section{Data Availability}

No data were used to support this study.

\section{Conflicts of Interest}

The authors declare that there are no conflicts of interest.

\section{Acknowledgments}

This work was supported by the National Natural Science Foundation of China (no. 61803147), the Key Scientific and Technological Project of Henan Province (no. 182102310799), and the Foundation of Henan Educational Committee (no. 18A580003).

\section{References}

[1] M. Song, G. Zhang, W. Zeng, J. Liu, and K. Fang, "Railway transportation and environmental efficiency in China," Transportation Research Part D: Transport and Environment, vol. 48, no. 10, pp. 488-498, 2016.

[2] R. Nuhodzic, D. Macura, and N. Bojovic, "One approach for management rail marketing strategies," Economic Computation \& Economic Cybernetics Studies \& Research, vol. 44, no. 11, pp. 237-256, 2010.

[3] Z. Jiajun, G. Jingwei, and Z. Hengying, "A research on the asymmetric growth of rail freight volume in China," Railway Freight Transport, vol. 37, no. 11, pp. 22-27, 2019.

[4] B. A. Pasternack, "Optimal pricing and return policies for perishable commodities," Marketing Science, vol. 4, no. 2, pp. 166-176, 1985.

[5] A. A. Tsay, "The quantity flexibility contract and suppliercustomer incentives," Management Science, vol. 45, no. 10, pp. 1339-1358, 1999.

[6] M. D. Eriksen, H. B. Fout, and M. E. Palim, "Contract price confirmation bias: evidence from repeat appraisals," The Journal of Real Estate Finance and Economics, vol. 60, no. 1-2, pp. 77-98, 2020.

[7] J. S. Rosenblatt, S. I. Park, and K. Y. Shin, "A quantity flexibility contract model for a system with heterogeneous suppliers," Computers \& Operations Research, vol. 41, no. 1, pp. 98-108, 2014.

[8] J. Xu, M. C. Gürbüz, Y. Feng et al., "Optimal spot trading integrated with quantity flexibility contracts," Production and Operations Management, vol. 29, no. 6, pp. 1532-1549, 2020.

[9] X. Chunlin, M. Weimin, and S. Fengwu, "Competitive analysis of the quantity flexibility contract in an on-line situation," International Journal on Information, vol. 14, no. 4, pp. 1111-1120, 2011.

[10] C. Van Delft and J. Vial, Quantitative Analysis of Multi-Periodic Supply Chain Contracts, HEC Paris, Paris, France, 2001.

[11] N. Wan and X. Chen, "Multiperiodic procurement problem with option contracts under inflation," Mathematical Problems in Engineering, vol. 2016, Article ID 4041871, 11 pages, 2016.

[12] W. Zhang, Y. Z. Hua, and B. Huo, "Dynamic multi-technology production-inventory problem with emissions trading," IIE Transactions, vol. 48, no. 2, pp. 110-119, 2015.

[13] G. D. Eppen and A. V. Iyer, "Backup agreements in fashion buying-the value of upstream flexibility," Management Science, vol. 43, no. 11, pp. 1469-1484, 1997.

[14] R. Adland, H. Ameln, and E. A. Brnes, "Hedging ship price risk using freight derivatives in the drybulk market," Journal of Shipping and Trade, vol. 5, no. 1, pp. 1-18, 2020.

[15] S. B. Lee, S. Thomas, and Y. Ho, "Term structure movements and pricing interest rate contingent claims," Journal of Finance, vol. 41, no. 5, pp. 1011-1029, 1986.

[16] T. Matsuda and A. Takemura, "Game-theoretic derivation of upper hedging prices of multivariate contingent claims and submodularity," Japan Journal of Industrial and Applied Mathematics, vol. 37, no. 1, pp. 213-248, 2020. 
[17] K. Kentia and C. Kühn, "Nash equilibria for game contingent claims with utility-based hedging," SIAM Journal on Control and Optimization, vol. 56, no. 6, pp. 3948-3972, 2018.

[18] J. Guo, "The optimal hedging ratio for contingent claims based on different risk aversions," Open Journal of Business and Management, vol. 7, no. 2, pp. 447-454, 2019.

[19] B. Dawn, B. Yehuda, and A. Ravi, "Coordination and flexibility in supply contracts with options dawn barnes-schuster," Manufacturing \& Service Operations Management, vol. 4, no. 3, pp. 171-207, 2020.

[20] H. Bester and D. Krähmer, "Exit options in incomplete contracts with asymmetric information," Journal of Economic Theory, vol. 147, no. 5, pp. 1947-1968, 2012.

[21] L. Di Corato, M. C. Dosi, and M. Moretto, "Multidimensional auctions for long-term procurement contracts with early-exit options: the case of conservation contracts," European Journal of Operational Research, vol. 267, no. 1, pp. 368-380, 2018.

[22] Y. Yoshida, "A discrete-time model of American put option in an uncertain environment," European Journal of Operational Research, vol. 151, no. 1, pp. 153-166, 2003.

[23] J. E. Hilliard and J. Hilliard, "A jump-diffusion model for pricing and hedging with margined options: an application to brent crude oil contracts," Journal of Banking \& Finance, vol. 98, no. 1, pp. 137-155, 2019.

[24] B. Duan, Y. K. Xin, and Y. Zhong, "Optimal dispatching of electric vehicles based on smart contract and internet of things," IEEE Access, vol. 8, pp. 9630-9639, 2020.

[25] D. Barnes-Schuster, Y. Bassok, and R. Anupindi, "Coordination and flexibility in supply contracts with options," Manufacturing \& Service Operations Management, vol. 4, no. 3, pp. 171-207, 2002.

[26] F. Cheng, M. Ettl, G. Y. Lin, M. Schwarz, and D. David, Yao Flexible Supply Contracts via Options, IBM Resarch, Yorktown Heights, NY, USA, 2003.

[27] W. Xing, L. S. Wang, and L. Liu, "Optimal ordering and pricing strategies in the presence of a B2B spot market," European Journal of Operational Research, vol. 221, no. 1, pp. 87-98, 2012.

[28] Q.-Z. Wang and D.-B. Tsao, "Supply contract with bidirectional options: the buyer's perspective," International Journal of Production Economics, vol. 101, no. 1, pp. 30-52, 2006.

[29] J. Cai, J. M. Zhong, and W. Huang, "Coordinating VMI supply chain under yield uncertainty: option contract, subsidy contract, and replenishment tactic," International Journal of Production Economics, vol. 185, no. 3, pp. 196-210, 2017.

[30] Z. Liu, S. Hua, and X. Zhai, "Supply chain coordination with risk-averse retailer and option contract: supplier-led vs. retailer-led," International Journal of Production Economics, vol. 223, no. 5, pp. 1-22, 2020.

[31] H. Rolf, Capacity options for revenue management-theory and applications in the air cargo industry, Ph.D. thesis, WHU Otto Beisheim School of Management, Vallendar, Germany, 2006.

[32] S. Koekebakker, S. R. Sødal, and S. Sodal, "Pricing freight rate options," Transportation Research Part E: Logistics and Transportation Review, vol. 43, no. 5, pp. 535-548, 2007.

[33] T. Soltani, A. Chockalingam, J. C. Fransoo et al., "Transporting commodities: hedging against price, demand and freight rate risk with options," SSRN Electronic Journal, 2015.

[34] I. Kyriakou, N. C. Pouliasis, and K. Andriosopoulos, "Freight derivatives pricing for decoupled mean-reverting diffusion and jumps," Transportation Research Part E: Logistics and Transportation Review, vol. 108, no. 12, pp. 80-96, 2017.

[35] R. Ådland, H. Jia, and S. Koekebakker, “The pricing of forward ship value agreements and the unbiasedness of implied forward prices in the second-hand market for ships," Maritime Economics \& Logistics, vol. 6, no. 2, pp. 109-121, 2004.

[36] R. Adland and H. Jia, "Simulating physical basis risks in the capesize freight market," Maritime Economics \& Logistics, vol. 19, no. 2, pp. 196-210, 2017.

[37] J. W. Guo and Q. Y. Peng, "Railway freight pricing model based on trigeminal tree," Journal of Transportation Systems Engineering \& Information Technology, vol. 14, no. 4, pp. 194-200, 2014.

[38] J. W. Guo and Q. Y. Peng, "Pricing model with jump-diffusion process," Journal of Transportation Systems Engineering \& Information Technology, vol. 15, no. 2, pp. 195-202, 2015.

[39] J. W. Guo, J. Wang, Q. L. Li et al., "Construction of prediction model of neural network railway bulk cargo floating price based on random forest regression algorithm," Neural Computing and Applications, vol. 31, no. 12, pp. 8139-8145, 2029.

[40] J. Guo, Z. Xie, Q. Li, S. Zhan, and J. Xu, "Railway passenger flow recognition algorithm for terminal station based on cost theory and automatic frequency control," IEEE Access, vol. 8, no. 2, pp. 26885-26892, 2020. 